\title{
A Full-Scale Application of Slope Stabilization via Calcite Bio-Mineralization Followed by Long-Term GIS Surveillance
}

\author{
Dimitrios Terzis, Ph.D. ${ }^{1}$; Lyesse Laloui, Ph.D. ${ }^{2}$; Sarah Dornberger ${ }^{3}$; and Ray Harran ${ }^{4}$ \\ ${ }^{1}$ Soil Mechanics Laboratory, Swiss Federal Institute of Technology, Lausanne (EPFL), \\ Lausanne; MeduSoil LLC, Ch de la Raye, Ecublens. E-mail: dimitrios.terzis@epfl.ch \\ ${ }^{2}$ Soil Mechanics Laboratory, Swiss Federal Institute of Technology, Lausanne (EPFL), \\ Lausanne. E-mail: lms@epfl.ch \\ ${ }^{3}$ Soil Mechanics Laboratory, Swiss Federal Institute of Technology, Lausanne (EPFL), Lausanne \\ ${ }^{4}$ Soil Mechanics Laboratory, Swiss Federal Institute of Technology, Lausanne (EPFL), Lausanne
}

\begin{abstract}
The field of soil bio-improvement, through microbial-induced calcite mineralization, has gained significant momentum in scientific literature in the past years. The phenomenon, which is inspired from natural environments, has been extensively applied at laboratory bench-scale, leading to a surge of expectations around its potential fit as a mainstream solution to real-world construction and environmental problems. The present study aims to break out of the laboratory and deliver a benchmark, large-scale application of ground bio-reinforcement which was designed and implemented in the canton of Vaud, Switzerland. The work aims to mitigate landslide risk in a slope hit by extreme rainfall in early 2018. This resulted in increased pore water pressure within the failure surface, therefore reducing the soil's effective shear strength and triggering the slip of roughly 3,000 cubic meters of earth mass. A grouting solution was designed to induce the bio-mineralization of calcite binders within the targeted slip zone. In order to present obtained results in the best possible light, we combine laboratory tests, in situ monitoring, microstructural inspections, and post-stabilization aerial surveillance. Obtained data reveal slower displacement rates for the bio-stabilized zone compared to the rest of the slope. Overall, our global analysis aims to offer new prospects towards bio-mediated geotechnical practice under real-life conditions.
\end{abstract}

\section{INTRODUCTION}

An alternative method to artificial cementation of soils has emerged in the past decade based on bio-mediated urea hydrolysis, which has led the way towards adopting bio-inspired approaches to ultimately tackle problems of geotechnical interest. Terms such as "bio-cement", "bio-grouting" and "MICP", which stands for Microbial-Induced Calcite Precipitation, have gained significant momentum in scientific literature (Dejong et al., 2006, van Paassen et al., 2010, Dejong et al., 2013, Terzis and Laloui, 2018, Terzis and Laloui, 2019). These technologies eventually carry the physical potential to improve the mechanical properties of soils. However, it is widely appreciated by engineers as early stage methods, still under development, with critical uncertainties and environmental concerns involved.

The principles of ground bio-stabilization are not new to engineers or researchers. The key reactant element in the process, i.e. urea $\mathrm{CO}\left(\mathrm{NH}_{2}\right)_{2}$, is extensively applied in agriculture as a stable, organic fertilizer which provides nitrogen to crops, through its hydrolysis, and increases their yield. During ureolysis, i.e. urea breakdown, $\mathrm{NH}_{4}$ and $\mathrm{CO}_{2}$ are formed. Soil microorganisms, which bear the urease enzyme, catalyze this reaction and speed it up by a factor 
of $10^{14}$, compared to the non-catalyzed one. Overall, calcite is an abundant mineral in the subsurface and its formation, under controlled environments as a soil binder, is considered to offer engineers a substantial tool towards improving the mechanical performance of soils. But are the claimed benefits real? The goal of this work is to provide evidence towards addressing the feasibility, efficiency and overall performance of ground bio-stabilization through this realworld, large-scale application.

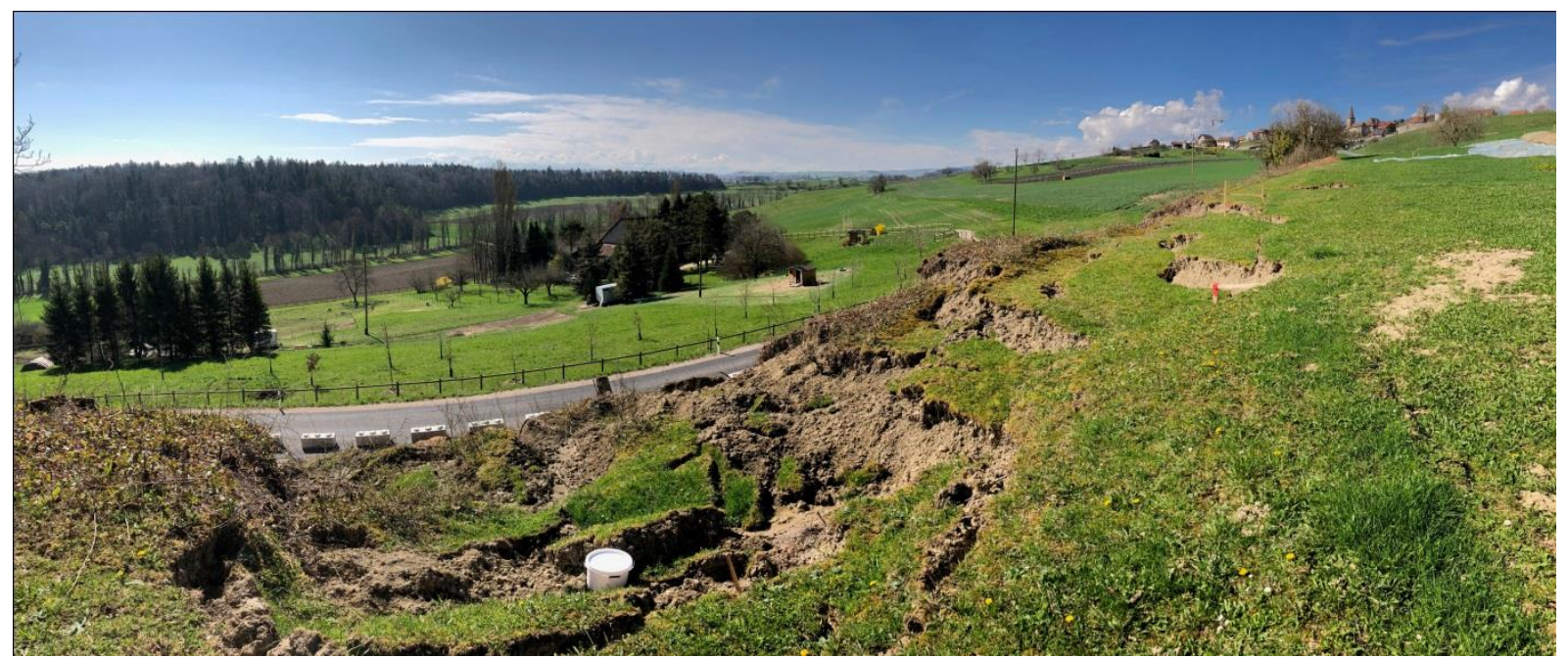

Figure 1. The collapsed earth mass blocked part of the road located at the bottom of the slope for over ten months, until rehabilitation works were put in place.

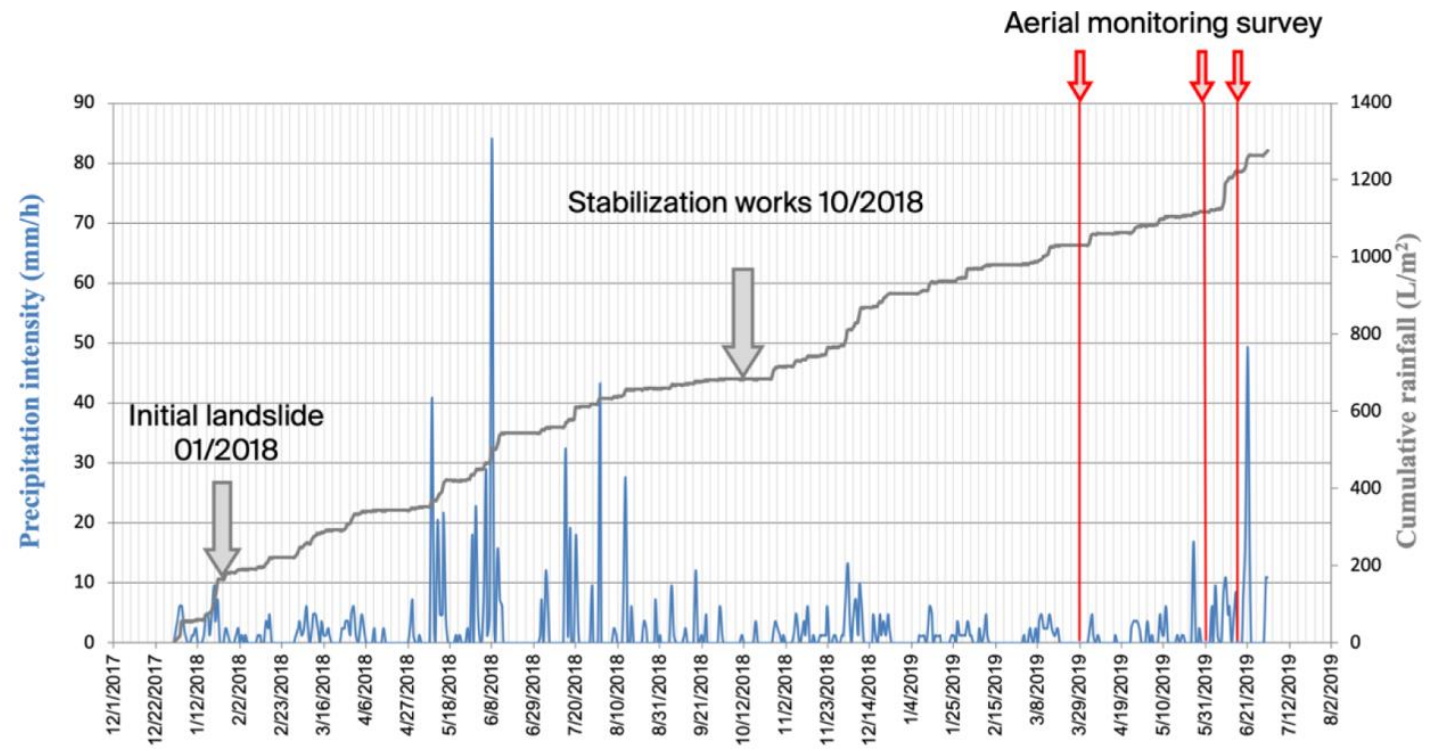

Figure 2. Rainfall data over the span of 18 months indicating the triggering of the slide, the period of bio-stabilization works and the aerial monitoring surveys.

\section{MATERIALS AND METHODS}

On January $21^{\text {st }} 2018$, after several days of heavy rainfall, a landslide of around $2000 \mathrm{~m}^{3}$ took place near the village of Rances (VD, Switzerland) (Figure 1). The collapsed, 100-meter-long 
land segment, with a width span ranging from 5 to $15 \mathrm{~m}$, slid across a failure surface located at a depth of 4-4.5 meters according to inclinometric data. Rainfall data for the pre-slide period, as well as for the following 18 months since the event occurred are presented in Figure 2 along with the carried-out stabilization and monitoring interventions.
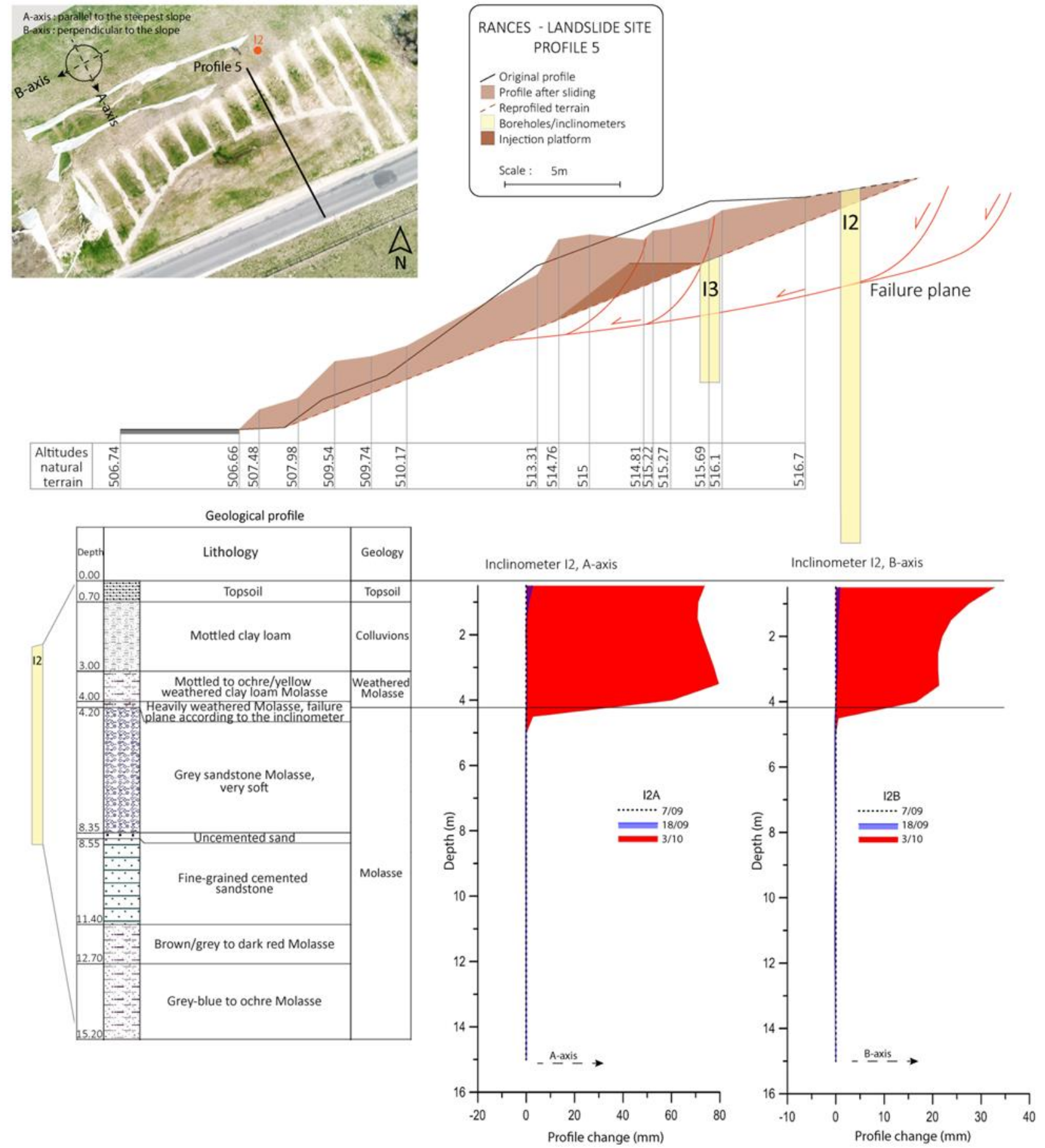

Figure 3. Cross section of the slope profile with presentation of the stratigraphy and inclinometric data. 
According to available public data (canton de Vaud), the site is located in a zone of low velocity landslides, moving at an average rate of $0-2 \mathrm{~cm}$ per year. However, intense rainfall which occurred in the weeks preceding the event (Agriscope) resulted into the slope slip. First assessments showed that the rainfall resulted in accumulated pore pressure within the soil, thereby decreasing its shear strength and triggering the slip.

The displacement profile versus depth of I 2 reveals significant movement of the overburden volume against a stable substrate which is composed of the much more rigid grey Molasse (Figure 3). A zone of weathered, disaggregated Molasse was therefore identified as the potential slip plane. The rock type present below the superficial colluvial deposits was the Chattian Molasse. Its permeability value is $10^{-7} \mathrm{~m} / \mathrm{s}$. The silty clayey soil, overlying the Chattian Molasse and encompassing the slip zone of weathered, disaggregated Molasse, is known to have very low permeability of approximately $10^{-7}-10^{-8} \mathrm{~m} / \mathrm{s}$. However, the presence of local fissures imply that permeability varies locally, and surface infiltration mechanisms exist which would serve as flow channels for the diffusion of the reactant elements through the determined grid of injection boreholes. Public data on existing geological surveys in the area (source geo.vd.ch) reveal that the studied, sliding zone is composed of silty clay with rounded alpine gravels and few rigid Jurassic fragments (limestone) of fairly high plasticity.

\begin{tabular}{ccc} 
& Table 1 Composition of the reactive agent & \\
Element & Unit & Concentration \\
\hline Urea & $\mathrm{mmol} / \mathrm{L}$ & 50 \\
Calcium Chloride & $\mathrm{mmol} / \mathrm{L}$ & 40 \\
Sporosarcina Pasteurii & $\mathrm{cfu} / \mathrm{ml}$ & $1,500,000$
\end{tabular}

Due to the slope's steepness, it was necessary to build a temporary platform to allow operations to take place (Figure 3). It should be noted that the slope shown in Figure 3 corresponds to the condition after implementation of the re-profiling works and that the initial slope was above $30^{\circ}$. In total, 51 boreholes of $53 \mathrm{~mm}$ diameter were drilled to a depth of 4.5 meters reaching the determined slip surface to induce the formation of bio-mineralized calcite. Boreholes were not cased and PVC injection pipes (without sleeve) were used with slots every $50 \mathrm{~cm}$.

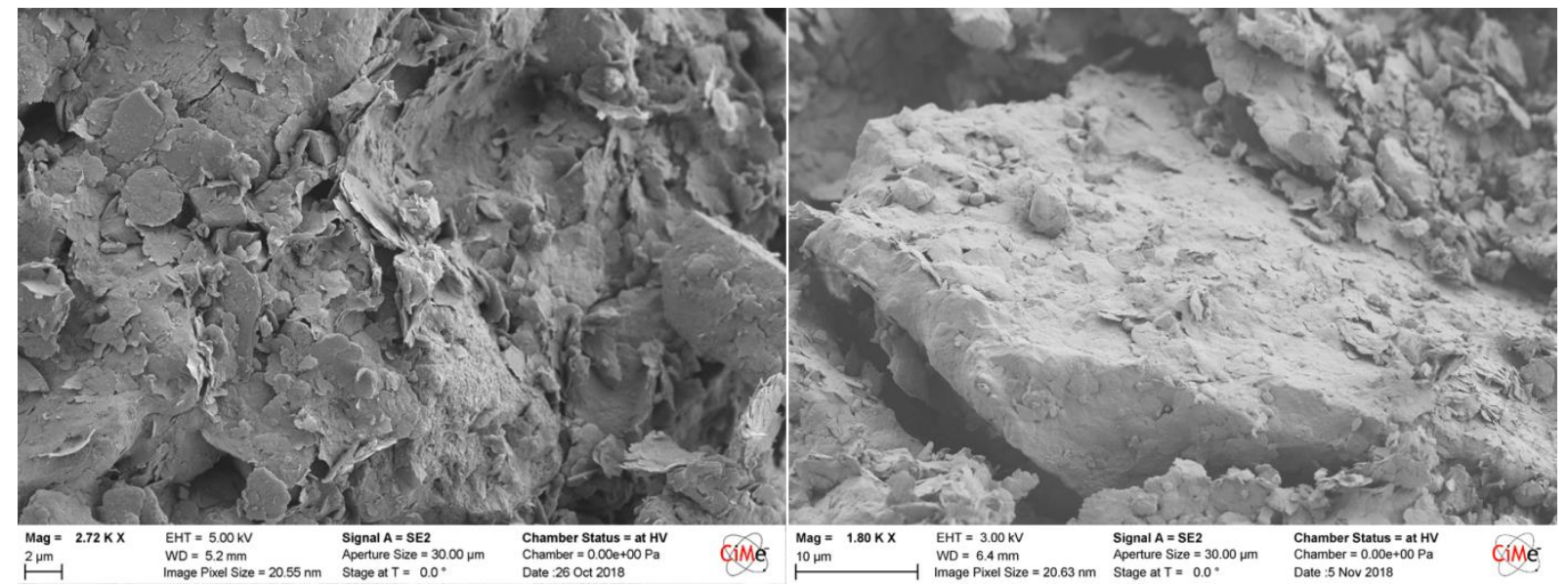

Figure 4. SEM observations for the natural (prior to biostabilization) clayey soil. 
The width of the platform ( 3 meters) allowed for safe circulation and drilling operations and its total length (17 meters) was determined in order to influence the half part of the slope and compare later its response with that of the second half, which was not subjected to biostabilization. The density of the adopted injection mesh was determined based on the low permeability of the targeted soil to achieve homogenous repartition of the total injected volume across the targeted zone. Stop-flow injections were performed where each borehole was supplied with $10 \mathrm{~L}$ of the reactive agent (i.e. the total borehole volume) for a total of eight injections. Supply took place via gravity flow under a hydraulic head of $2 \mathrm{~m}$. This corresponds to the altitude difference between the top of the landslide, where the reservoir tanks were placed, and the platform.

No additional pumping pressure was necessary to perform injections. After supplying the batches of reactant agents, the filled boreholes were left to drain towards the surrounding soil until the next batch of stop-flow injections took place. Injections lasted 4 days in total, with two batches supplied every day. On the fifth and last day of operations, soil samples were collected and analyzed in the laboratory for their calcite content and microstructure. To overcome the fact that all the installed inclinometers had reached the maximum shear limit $(15 \mathrm{~cm})$, even before the stabilization works took place, we mobilize a system of aerial surveillance via drones and subsequent $3 \mathrm{D}$ reconstruction of the slope surface to monitor displacements.

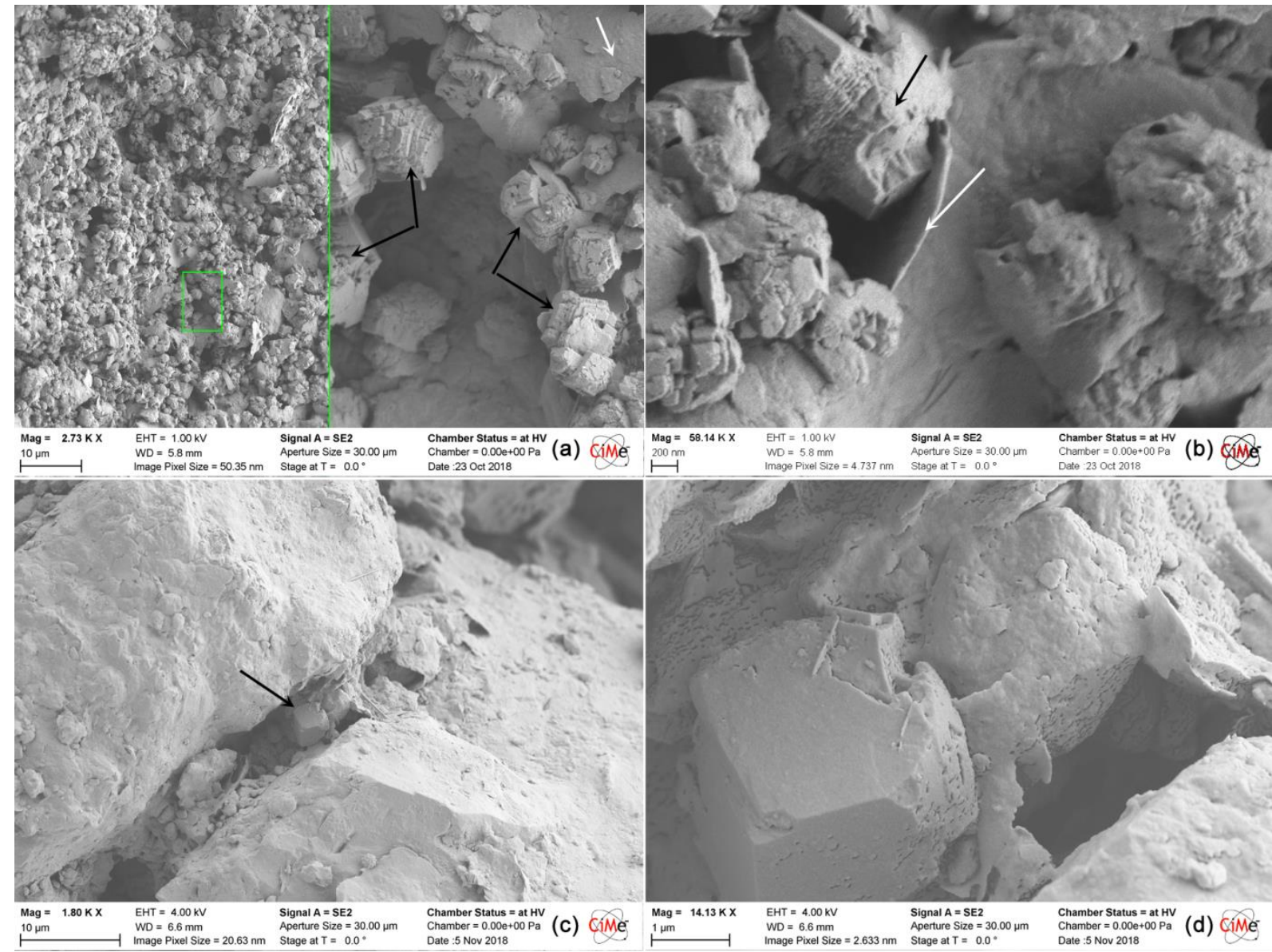

Figure 5. Post-biostabilization textural observations; black arrows indicate cubic calcite particles and white arrows clay platelets. 


\section{RESULTS}

Samples were collected from the targeted zone post-biostabilization, when the platform was removed, to study the calcite content and the improved microstructure. Figure 4 illustrates the soil's natural condition, with thin clay platelets being identified as well as pores of few micrometers in diameter (right).

Nanoscale observations of the post-treatment soil condition revealed a strong presence of cubic-shaped calcite crystals among the platelets of clay particles (Figure 5) which exhibit edges that reach a few micrometers. Sand-clay mixtures have been studied under MICP in the works by (Jiang et al., 2016 and Cardoso et al., 2018). However, to the authors' best knowledge, no previous study has shed light onto the growth of individual calcite particles, result of reported bio-calcification, on clay particles at the nanoscale. A hypothesis adopted in light of the observed microstructural features, is that the presence of calcite crystals among floccules of clay offers a sign of cation adsorption and of interactions which occur at the particle level when calcium is attracted by the negatively charged, thin clay layers. The mechanism of cation adsorption on clay surfaces, when these are in contact with solute-rich media, is believed to affect the expansion of tactoids (i.e. superstructures of clay particles) and the generation of micro-porosity which can provide additional space for the development of calcite crystals. Natural soil, i.e. soil in its pretreatment condition, had an average carbon content of $16 \%$, with $27 \%$ of this fraction representing organic carbon and the rest inorganic matter. Post-treatment calcite measurements reveal an increase in calcite content in the range $0.8-2.8 \%$ of the total solid mass, for all samples collected from the vicinity of boreholes (distance $20 \mathrm{~cm}$ ) and reaches $18 \%$ for the borehole walls. Additional analyses of TOC and TIC reveal a decrease in the organic carbon fraction which now reaches $16 \%$, compared to $27 \%$ for the untreated, natural soil. This variation is attributed to the mineralization of additional inorganic carbon in the form of bio-mediated calcite particles.

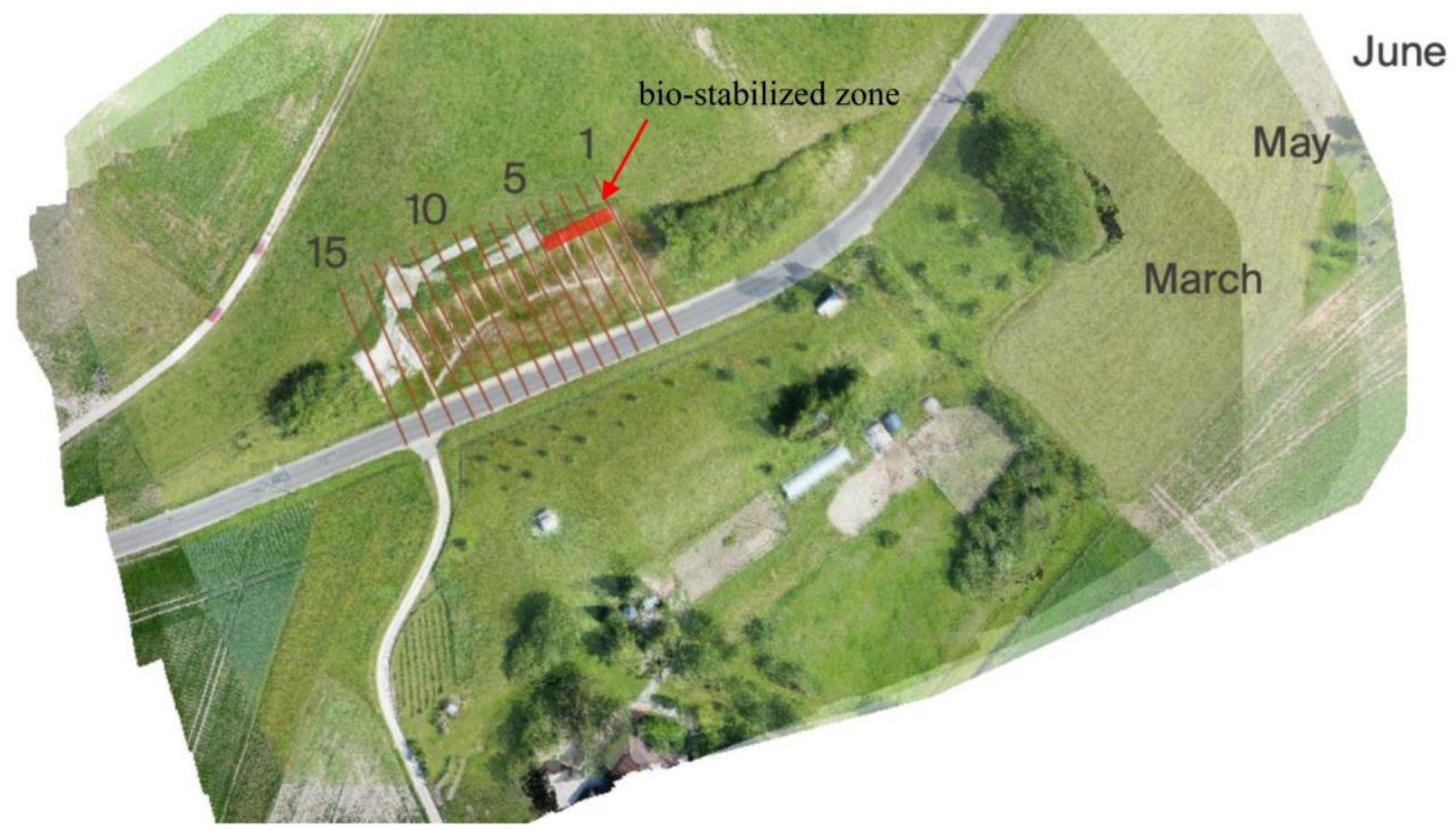

Figure 6. Aerial view of the scanned area of landslide during March, May and June. Red lines indicate the profiles analyzed in Figure 7. 


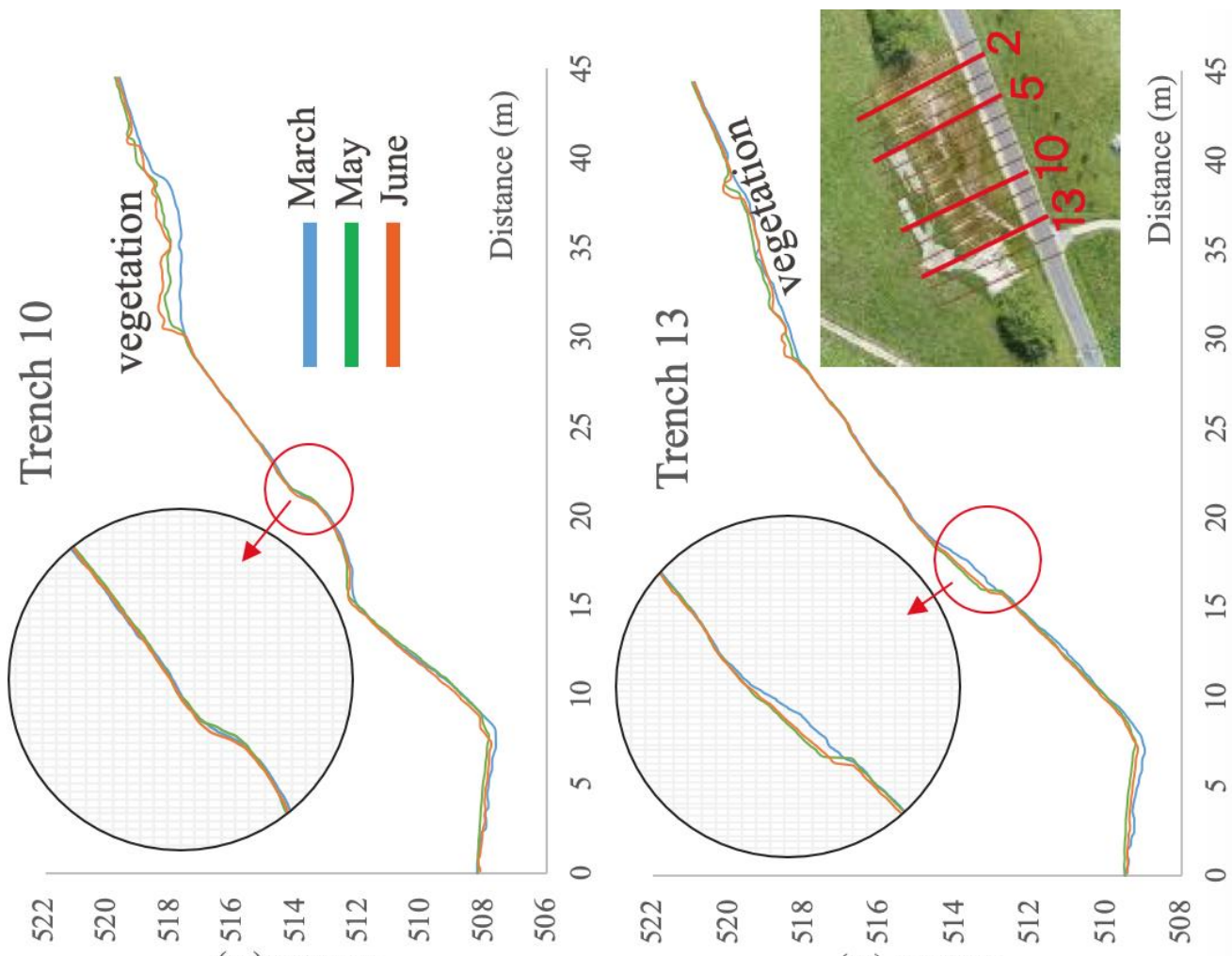

(ш) әрп!!ा

(ய) әрп!ฺए

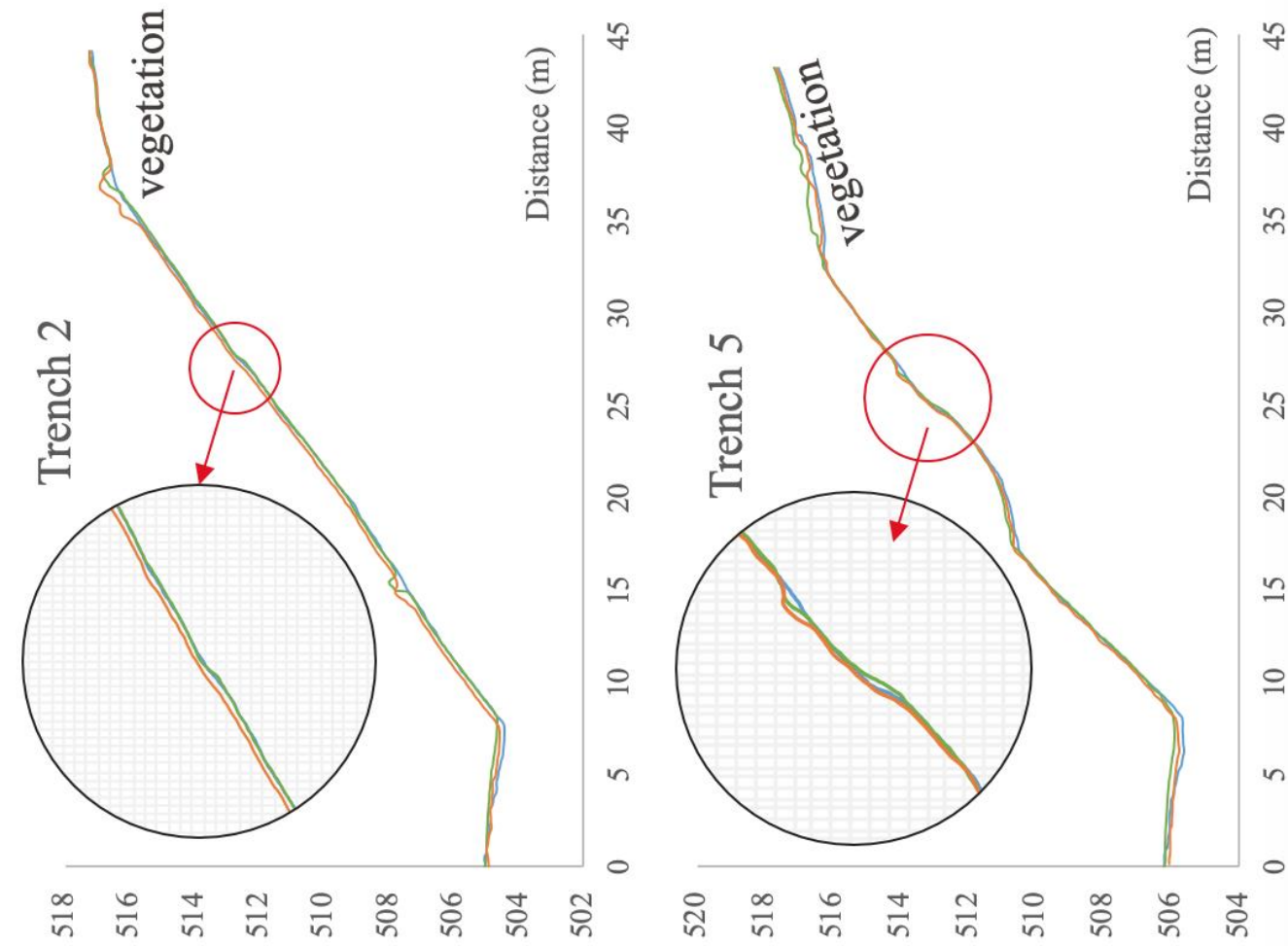

(w) әрп!!

(ш) әрп!ฺा

Figure 7. Slope profiles obtained via 3D surface reconstruction revealing sliding profiles for trenches $2,5,10,13$. Inlets focus on the slope deformation (inlet grid $25 \times 25 \mathrm{~cm}$ ). 
Aerial surveillance of the slope allows for the reconstruction of the 3D surface using PIX4D software. A bird's view of the slope, as well as the installed drainage trenches (red lines), is shown in Figure 6. The trenches (which have a depth of 1 meter) are used as reference profiles for the comparison of the slope for the period following the stabilization works to evaluate the long-term behaviour of the slope with respect to rainfall events (Figure 2). The 3D surface reconstruction reveals the evolution of the slope profile between March and June 2018 for four selected trenches (Figure 7). Overlaying of the obtained point clouds took place via reference to three fixed surface marks on the road and adjacent farm. A clear sliding zone is identified (shown in arrows), with displacement values found more pronounced for profiles 10 and 13 , which correspond to the non-biostabilized zone, with respect to profile 5 which yields displacement rates lower than $1 \mathrm{~mm} /$ day.

\section{CONCLUSIONS}

The present work implemented a series of measures for the application, monitoring and, ultimately, understanding of soil bio-stabilization under real-world conditions. Provided data suggest that the technique can become an efficient tool towards improving the structure and performance of fine soils, which were previously considered as the technique's bottleneck. Important insight is provided into the micro-structure of bio-reinforced clay and the physical mechanism behind the solute adsorption and subsequent mineralization of $\mathrm{CaCO}_{3}$ particles on thin clay particles. To successfully implement MICP in fine soils, a possible modification compared to the case of granular soils could be proposed: $\mathrm{Ca}^{2+}$-rich solutions can precede the introduction of urea as a means of pre-conditioning the area of treatment before injecting $\mathrm{CO}_{3}{ }^{2-}{ }_{-}$ rich media. Post-treatment slope displacements, which were quantified through drone surveillance suggest slower movement for the bio-treated part compared to the rest of the sliding zone. Overall, the work presented herein attempted a major leap from the laboratory bench towards real-life geo-environmental applications and benchmarking with classical geoenvironmental stabilization methods. Findings contribute towards new and realistic developments in the quest for novel and sustainable solutions to the pressing need of ground stabilization.

\section{ACKNOWLEDGEMENTS}

This project has received funding from the European Research Council (ERC) under the European Union's Horizon 2020 research and innovation program (grant agreement No 788587).

\section{REFERENCES}

Agroscope, "Données météorologiques," Confédération Suisse, [Online]. Available: http://www.agrometeo.ch/fr/meteorology/datas. [Accessed November 2018].

Canton de Vaud, "Guichet cartographique cantonal," December 2018. [Online]. Available: http://www.geo.vd.ch/.

Cardoso, R., Pires, I., Duarte, S.O. and Monteiro, G.A., 2018. Effects of clay's chemical interactions on biocementation. Applied Clay Science, 156, pp.96-103.

DeJong, J.T., Fritzges, M.B. and Nüsslein, K., 2006. Microbially induced cementation to control sand response to undrained shear. Journal of Geotechnical and Geoenvironmental Engineering, 132(11), pp.1381-1392.

Dejong, JT, Soga, K, Kavazanjian, E, Burns, S, van Paassen, L, AL Qabany, A, Aydilek, A, 
Bang, SS, Burbank, M, Caslake, LF, Chen, CY, Cheng, X, Chu, J, Ciurli, S, Esnault-Filet, A, Fauriel, S, Hamdan, N, Hata, T, Inagaki, Y, Jefferis, S, Kuo, M, Laloui, L, et al. 2013, 'Biogeochemical processes and geotechnical applications: Progress, opportunities and challenges' Geotechnique, vol. 63, no. 4, pp. 287-301.

Jiang, N.J., Soga, K. and Kuo, M., 2016. Microbially induced carbonate precipitation for seepage-induced internal erosion control in sand-clay mixtures. Journal of Geotechnical and Geoenvironmental Engineering, 143(3), p.04016100.

Terzis, D., \& Laloui, L. (2019). A decade of progress and turning points in the understanding of bio-improved soils: A review. Geomechanics for Energy and the Environment, 19, 100116.

Terzis, D. and Laloui, L., 2018. 3-D micro-architecture and mechanical response of soil cemented via microbial-induced calcite precipitation. Scientific reports, 8(1), p.1416. van Paassen, L.A., Ghose, R., van der Linden, T.J., van der Star, W.R. and van Loosdrecht, M.C., 2010. Quantifying biomediated ground improvement by ureolysis: large-scale biogrout experiment. Journal of geotechnical and geoenvironmental engineering, 136(12), pp.1721 1728. 